Document downloaded from:

http://hdl.handle.net/10251/62787

This paper must be cited as:

Serrano Jareño, MA.; Cañada, J.; Moreno, J. (2013). Erythemal ultraviolet solar radiation doses received by young skiers. Photochemical \& Photobiological Sciences. 12(11):19761983. doi:10.1039/c3pp50154j.

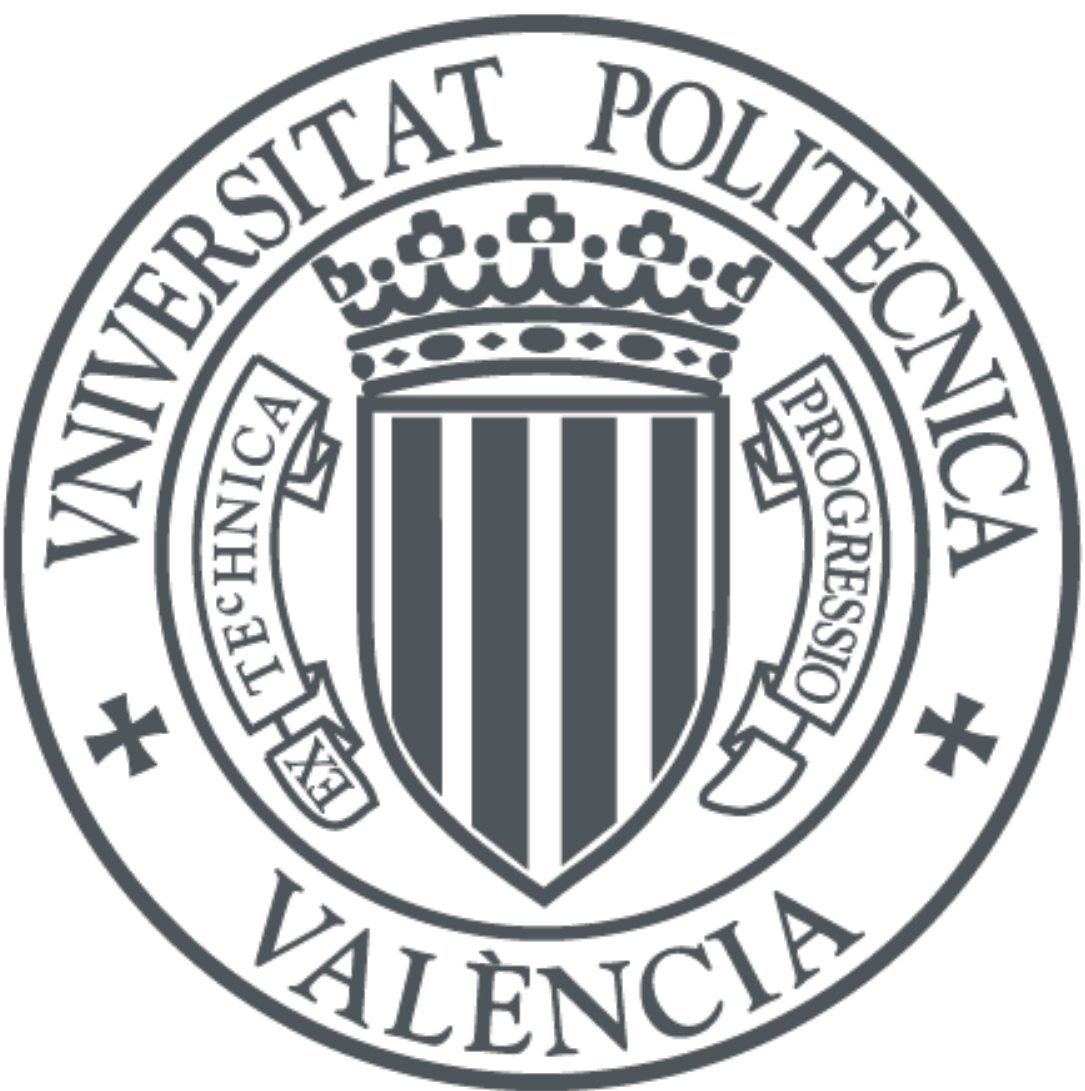

The final publication is available at

http://dx.doi.org/10.1039/c3pp50154j

Copyright Royal Society of Chemistry

Additional Information 


\title{
Erythemal Ultraviolet Solar Radiation Doses Received by
}

\section{Young Skiers}

\author{
María-Antonia Serrano *, Javier Cañada *, Juan Carlos Moreno
}

Instituto de Ingeniería Energética, Universitat Politècnica de València, Camino de Vera s/n, 46022 Valencia, España

Members of the Valencia Solar Radiation Research Group

*Corresponding author: mserranj@fis.upv.es (Maria Antonia Serrano),

Tel: +34-963877007; Fax: +34-963879896.

The purpose of this study is to quantify UV exposure of young skiers in their training or recreational schedules, using VioSpor personal dosimeters and the results indicated that this group is exposed to UV radiation levels that can potentially cause skin damage and erythema and increase the risk of skin cancer in later life.

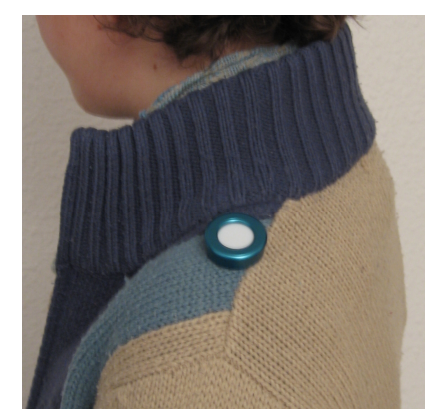

- Professor Dr. Javier Cañada passed away in January when the study was finished. 


\begin{abstract}
Children are a special group since the epidemiological evidence indicates that excessive exposure to sunlight at an early age increases the risk of skin cancer in later life. The purpose of this study is to quantify children's UV exposure when skiing, using dosimeters (VioSpor) placed on the shoulders of 10 participants. The children received a median daily Standard Erythema Dose of 2.1 within a range of 4.9-0.71, this being approximately $35 \%$ of the calculated $24 \mathrm{~h}$ ambient $\mathrm{UV}$ radiation on the horizontal plane. According to the results obtained, young skiers are exposed to UV radiation that can potentially cause skin damage and erythema and increase the risk of skin cancer in the course of a lifetime. These findings emphasise the need for adequate protective measures against solar radiation when skiing. The results also suggest that sunprotection campaigns should be undertaken aimed at children engaged in outdoor sports, including winter activities.
\end{abstract}

Keywords: Erythemal ultraviolet radiation; UV exposure; personal dosimetry; exposure ratio; 


\section{Introduction}

Solar ultraviolet radiation (UVR) has a significant influence on the health of humans, especially that of children, who are more susceptible to UV exposure. The harmful effects of excessive sun exposure are well known, as it can cause erythema, sunburn, skin photo aging, and especially carcinogenesis (melanoma and non-melanoma skin cancers $)^{1-4}$.

Many studies show that skin cancer and melanoma are an important problem in Spain and the rest of Europe in the last 20 years, being that its incidence has increased significantly $y^{5-8}$. On the one hand, although non-melanoma skin cancer is the most common malignant tumour of all, it has been shown to rarely cause death ${ }^{9}$. On the other hand, melanoma is responsible for up to $80 \%$ of all deaths from skin cancer, and in Spain its mortality rate has quadrupled in the last 35 years ${ }^{10}$, although only a slight increase in mortality has been observed in the last decade. Despite this, the mortality rate from melanoma in Spain is still among the lowest in Europe, since Spain presented an age-standardised mortality rate (world standard population) of 1.0 in 2008 , lower than in Europe (1.5) and Northern Europe (2.0) ${ }^{11}$, probably due to the population's skin characteristics.

It is therefore important to intensify efforts to reduce harmful exposure to UVR, particularly among children and adolescents. Children require special protection, since their skin is thinner and more sensitive to sunlight than that of an adult, so that even a short time outdoors at noon can cause erythema. Also it must be taken into account that excessive UV exposure early in life means that there are plenty of time ahead to develop the possible skin cancer. Children are exposed to sunlight for considerable periods and it has been estimated that $25 \%$ of an individual's cumulative exposure to UVR occurs during childhood and adolescence ${ }^{12}$. They are therefore at a higher risk of suffering 
damage from exposure to UVR than adults. Although sunburn is also a melanoma risk factor among adults ${ }^{13,14}$, the epidemiological evidence indicates that excessive exposure to sunlight at an early age is an important factor in determining the risk of skin cancer in the course of a lifetime ${ }^{15-19}$. Melanoma is rare in children, but several studies have documented an increase in their incidence in children and adolescents ${ }^{19-21}$. Childhood melanoma risk factors are less well understood than in adults. Melanomas in younger individuals are thought to have a different pathology and have different risk factors, mainly genetic such as number of melanocytic nevi, family history of melanoma and immunosuppression, among others ${ }^{20-22}$. UV exposure is therefore the only known risk factor on which one can act to reduce the risk of skin cancer ${ }^{18}$. Athletes who spend a lot of time outdoors receive regular and significant solar UVR. Several studies on the frequency of skin melanomas in marathon runners ${ }^{23,24}$, cyclists $^{25}$, mountain guides ${ }^{26}$ and golfers ${ }^{27,28}$ reinforce the belief that outdoor activities can increase the risk of skin cancer. These studies focused on adults and there is little information on the risk of UVR-associated skin cancer in children. In 2011, Mahe et al. ${ }^{29}$ evaluated the relationship between UVR skin damage and outdoor sports in children under 11 years of age in a 2-year period. They observed a significantly higher occurrence of such UV related damage in children who practiced outdoor sports, confirming the opinion that outdoor activities are associated with high exposure to UVR.

But, on the other hand, we should also take into account the beneficial effects of sunlight on human health ${ }^{2,4}$, such as, for example, the synthesis of Vitamin $\mathrm{D}_{3}{ }^{30,31}$ essential for bone mineralization ${ }^{32}$. Appropriate vitamin D levels, besides being required for healthy bones, especially important in growing children, have also been suggested to be beneficial against the development of many diseases in adulthood ${ }^{33-36}$. 
Given the concern about the increased incidence of skin cancers, in 1999 a campaign called Euromelanoma ${ }^{37}$ was initiated in Europe, which is an annual campaign for skin cancer prevention that aims to make people aware of skin cancer prevention, early diagnosis and treatment. Since 2000, Spain has participated in several campaigns and they have made a valuable contribution to preventing cancer by the number of early detections and successfully excised melanomas ${ }^{38}$.

This paper presents the results of solar UV radiation readings taken from children during a ski school organized by the Universitat Politècnica de València in the ski resort of Panticosa (Huesca, Spain) during ski training activities.

\section{Materials and methods}

\section{Study location}

The study took place in the ski resort of Panticosa (Huesca) (coordinates $42^{\circ} 42^{\prime} 11^{\prime \prime} \mathrm{N}$ $0^{\circ} 16^{\prime} 29^{\prime \prime} \mathrm{W}$, at an altitude of $1800 \mathrm{~m}$ ) during a Snow School organized by the Universitat Politècnica de València (UPV) and involved a group of 10 children that took part in a series of four ski sessions $(27,28,29$, and 30 December 2010). Panticosa is strategically located in the heart of the Aragon Pyrenees, in the province of Huesca with $34 \mathrm{~km}$ of slopes between altitudes of $1500 \mathrm{~m}$ and $2200 \mathrm{~m}$. The skiers were raising the mountain in south direction respect to the sun and were descending to the north.

\section{Subjects and design}

Ten children, between 9 and 12 years old, participated in the study. Two children were of skin type II, 7 of skin type III and 1 of skin type IV and their skin type was identified by the monitors according to Fitzpatrick's classification ${ }^{39}$. The first meeting was with 
the head supervisor to explain the requirements of the study and to ask for volunteers. The head supervisor contacted with the parents of the children who were going to take part in the Snow school. Subject recruitment was made on a volunteer basis and included written consent from the parents of participating children. A subsequent meeting took place to inform the monitor group about the details of the study. Monitors were instructed not to change their activities during the measurement sessions and to continue with their normal routines. The group supervisor ensured that the children put on and removed the dosimeter at the programmed times and the type and duration of the outdoor activities and they completed a questionnaire in which they registered this information. The days when measurements were taken were found to be mostly clear, except on the $29^{\text {th }}$, on which there was $50 \%$ cloud cover. The dosimeters (VioSpor type I) were attached with a pin on top of the shoulder at the start of the sessions, covered at lunchtime and removed at the end of the activity. One dosimeter was used per subject per day from about 10:30 a.m. to 4:30 p.m. (except during the 1 p.m. -2 p.m. lunch hour).

\section{Personal UVR dosimeters}

A UV sensitive spore-film type I dosimeter (VioSpor , Bio-Sense, Bornheim, Germany $)^{40}$ was used in the study to measure personal UV doses. These dosimeters have been used effectively in many studies to monitor personal UV exposure in several outdoor activities ${ }^{41-46}$.

Details of the preparation of the dosimeters can be found in the following papers ${ }^{47,48}$. Basically, spores of a DNA repair-deficient strain of Bacillus subtilis form a film, which is covered by a filter system with a spectral sensitivity profile similar to the erythemal response of human skin, similar to the action spectrum of the Commission 
Internationale de $\mathrm{L}^{`}$ Eclairage $(\mathrm{CIE})^{49}$. According to the manufacturer, the measurement error is of $\pm 10 \%$, and it is the standard deviation (minimal erythema dose determined with VioSpor dosimeter and a spectroradiometer) to the spectroradiometer values. The working range for a dosimeter type I is 0.5-30 standard erythema dose (SED), in which $1 \mathrm{SED}$ is defined as an erythemal effective exposure of $100 \mathrm{~J} / \mathrm{m}^{2}$ when weighted with the CIE erythemal spectrum ${ }^{50}$.

The VioSpor system validation is performed by comparative measurements in-vivo ${ }^{51}$. The wavelength-specific calibration of VioSpor was made from measurements on the Okasaki spectrograph in $\operatorname{Japan}^{47,48}$. Additionally, VioSpor has also been validated by several instrument intercomparisons carried out under field conditions, in which VioSpor measurements were put together with the minimal erythema dose values estimated from spectroradiometer data ${ }^{52}$.

\section{Ambient solar UVR}

The readings were taken in an area where there were no measuring devices available to measure ambient solar erythemal UV irradiance. Since this irradiance on the horizontal plane is needed to calculate the exposure ratio, the ambient erythemal UVR for each day was obtained by means of two procedures, using satellite data from $\mathrm{OMI}^{53}$ and by simulating the FastRT ver 2.3 program ${ }^{54}$. The input data for this simulation were: geographical coordinates of the study site, type of surface (new snow), sky conditions (50\% cloud cover on $29^{\text {th }}$, and cloudless on the other days) and total column ozone. For each day, column ozone was obtained from data provided by the Ozone Monitoring Instrument ${ }^{55}$, and for the days without ozone data they have been estimated based on ozone data from the closest geographical coordinates. $1800 \mathrm{~m}$ was taken as the average altitude between the minimum elevation of $1500 \mathrm{~m}$ and the maximum of $2200 \mathrm{~m}$ above sea level. 
Erythemal UV daily dose satellite data were produced with the Giovanni online data system, developed and maintained by the NASA GES DISC ${ }^{56}$. The input data for the calculation were the geographical coordinates of the study site.

The time needed to cause sunburn each day for each skin type was calculated by the application of a module of the FastRT ver 1.2 program $^{57}$. The input data for the simulation, besides those listed above, was that sun exposure occurs around noon, i.e. between 12 and 2 p.m., and that the children have untanned skin, i.e. they have not previously been exposed to solar radiation.

Solar UVR can produce negative effects at certain levels, but in winter, low levels can cause vitamin $\mathrm{D}$ deficiency. The minimum exposure time ( $\mathrm{t}_{\mathrm{e}}-\mathrm{D}$ in minutes) necessary to produce $1000 \mathrm{IU}$ of vitamin $\mathrm{D}$, which is the minimum recommended daily amount, was calculated by FastRT ver 1.2 program ${ }^{57}$, assuming that $7.5 \%$ of the skin receives solar radiation (since the face and neck account for approximately $7.5 \%$ of total skin area according to the Lund and Browder chart for children 10 years old).

\section{Ethics}

The study was approved by the appropriate ethical committee related to the Universitat Politècnica de València and the parents of the children who participated in the study gave informed consent to the work.

\section{Statistical analysis}

Data were analysed using the Statgraphics Plus Statistical Package v5.1 software. In this study, the value of standardised skewness is not within the expected range for a normal distribution data, so the median is a better measure of central tendency for skewed distributions than the mean, and the data are expressed as median (maximum-minimum).

\section{Results}




\section{Ambient solar UVR}

Table 1 shows the simulated daily ambient erythemal UVR obtained from the FastRT program $^{54}$, ozone data and ambient erythemal UVR from the Ozone Monitoring Instrument ${ }^{53,55}$, and the maximum ultraviolet index (UVI) ${ }^{58,59}$ calculated from noonday erythemal UV irradiance $\left(\mathrm{W} / \mathrm{m}^{2}\right)$ indicated by the FastRT program ${ }^{54}$. As can be seen, the solar UVI, between 1 and 2, is a typically low winter value.

$>$ Table $1<$

As can be seen in Table 1 there are large differences between the ambient erythemal UVR obtained by the two methods, with significantly lower values for the erythemal UV daily dose provided by the OMI. According to the last OMI UVB Algorithm Documents $^{60}$ and confirmed by several authors ${ }^{61-63}$, OMI underestimates the values of the irradiance when there is a snow cover, because of the climatological surface albedo used by the OMI surface UV algorithm, which leads to overestimation of cloudiness ${ }^{61}$. For this reason we have chosen for calculations the data provided by the FastRT $\operatorname{program}^{54}$.

\section{Measured UV exposures}

Table 2 shows the children's median daily exposure and range (SED) for each day of the study, as measured by VioSpor dosimeters placed on the shoulder. The range shown gives a measure of the variability between the subjects. The $27^{\text {th }}$ and $29^{\text {th }}$ (partly cloudy), are the days of greatest variability, probably due to the important role played by clouds on actual UV irradiance on the $29^{\text {th }}$, since they can attenuate UV irradiance but can increase up to $25 \%$ under broken cloud conditions by reflected radiation from the cloud sides ${ }^{64}$. On the $27^{\text {th }}$, a greater range of activities than on the other days could be the cause of this variability. However, these differences cannot be considered 
statistically significant. It is also observed that on the $28^{\text {th }}$, the children received a median daily dose of 2.4 SED, close to the minimal erythema dose (MED) for skin type II (2.5 SED) for the four basic European skin types ${ }^{65}$.

$>$ Table $2<$

Table 3 shows the median dose received by each child; it can be seen that several children received a median daily dose above the MED for skin type II, which emphasizes the need for a sunscreen.

$>$ Table $3<$

The fraction of the ambient erythemal UVR to which children are exposed (ratio of the daily erythemal UV dose of each child and the corresponding $24 \mathrm{~h}$ ambient erythemal UV), called the exposure ratio (ER), is shown for the corresponding period in Table 2 and for each subject in Table 3. This median ER was 35\%, ranging from 12 to $96 \%$. Table 4 shows the exposure time ( $\mathrm{t}_{\mathrm{e}}-\mathrm{UVR}$ in minutes) for sunburn according to the skin type for the period of the study of UVI levels 1 and 2. It is observed that for UVI 2 days, a child with skin type III (Spanish) could be exposed to the sun for a maximum of 110 minutes without suffering erythema, while a fair-skinned (skin type II) person could only stay in the sun 89 minutes.

$>$ Table4<

With regard to vitamin $\mathrm{D}$ production, the minimum exposure time ( $\mathrm{t}_{\mathrm{e}}-\mathrm{D}$ in minutes) for vitamin D 1000 IU (minimum recommended daily amount) to be produced is shown in Table 5 for 29 December (partial cloudy) and the remaining days (cloudless).

$>$ Table $5<$

\section{Discussion}

Skiers suffer the harmful effects of the sun, due to the clear air at altitude and the fact that snow reflects about 80 percent of the sun's rays. UV irradiance increases with 
altitude due to reduced dispersive and absorptive material in the air. The effect of the surface albedo should also be taken into account, since at higher altitude the surface changes from vegetation to rock and snow is often present, so that the higher the albedo the higher the $\mathrm{UVR}^{66}$. This is known as the altitude effect (AE), and depends on the wavelength, solar elevation, atmospheric turbidity, cloudiness and the surface albedo ${ }^{67}$. The AE ranges in clear conditions for erythemal UV irradiance, for example, between $11-14 \% / \mathrm{km}$ in Granada (Spain) ${ }^{68}$ and between $7.2-11.3 \% / \mathrm{km}$ in the Swiss Alps ${ }^{69}$. This increased UV irradiance with altitude is of great importance for human exposure for the observed trend towards the increasing prevalence of melanoma ${ }^{70}$ in people who live at high altitudes and those who practice mountaineering and skiing.

Skiers thus receive significant UVR and numerous studies on exposure have been carried out on this group. Epidemiological studies have shown that skiers are at a higher risk of skin cancer ${ }^{71}$. In 2003, Rigel et al. ${ }^{72}$ studied skiers' UV exposure in Vail (Colorado) and found that they were exposed to UVR that can cause skin photoaging and potentially increase the risk of developing skin cancer. The subjects in this study received a mean UV dose of 6.21 SED (range 1.2-18.5 SED), when more than two thirds of the skiers were exposed to more than 5 SED per day. In 2008, Siani et al. ${ }^{73}$ studied erythemal UV doses received by a group of Italian alpine skiers with dosimeters placed on the forehead, and obtained a winter median ER of 54\%, with a range of 42 $70 \%$. They also studied the colorimetric parameters of the skin and found that skiers had significantly lower mean values, i.e. darker skin, after exposure to solar radiation than before exposure. In 2005, Allen and McKenzie ${ }^{74}$ measured UV exposure in a New Zealand ski resort and compared the results with values obtained at the same time in a nearby area at sea level using an electronic dosimeter. They found that the UV irradiance on horizontal surfaces in the ski resort was 20-30\% higher than at sea level 
and personal doses were significantly higher than those obtained on horizontal surfaces. The authors confirmed these results in a subsequent study ${ }^{75}$. In 2000, Moehrle and Garbe ${ }^{42}$ observed occupational exposure to UVR of mountain guides and ski instructors in the spring in the French Alps with dosimeters placed vertically on the head. They found the mountain guides received a mean daily dose of 29.75 SED (range 11-42.75 SED) and the ski instructors a mean daily dose of 15.25 SED (range 7-22 SED).

\section{Conclusions}

Differences in the design of individual UV studies, such as the position and type of dosimeters, latitude and altitude of study area, time of year, etc. make it difficult to compare results. However, if the ER is available it is used in the comparison to minimize the effects of these factors on the analysis.

Erythemal UV exposure in schoolchildren was analysed during skiing activities. The children's median daily exposure was 2.1 SED, with some registering over the MED for white skin. If we consider the range, which indicates variability for each student, almost all of the skin type II children would be above their MED on some days during the measurement period and a third of skin type III children would be above their MED (3.5 SED) at least one day of the study period.

Several studies ${ }^{76-78}$ show that parts of human body exposed close to the sun-normal direction are exposed to higher erythemal UVR than the UV dose measured on a horizontal plane. This occurs particularly at higher solar zeniths angles, for example, in the winter season, and in body areas close to the vertical position, such as the face, and it is accentuated if the surface is covered with snow.

The area of the body exposed to solar radiation in this sport is the face, which is in an approximate vertical plane, and it will receive a higher irradiance because the study took 
place in the winter season and in a snow cover area, than the top of the shoulder, which is in an approximate horizontal plane. Thus, the received dose in the face is higher than that measured by the dosimeters, so this should be taken into account to insist on the application of high protection facial sunscreen.

The children's mean daily exposure time during ski sessions was 276 minutes, which exceeds the safe erythema exposure time that produces erythema, except for type IV skinned children in days with the lowest UVI (Level 1) (Table 4). According to these results, children would have suffered sunburn and could have an increased risk of skin cancer later in life, if they were not taken adequate protection measures.

The median daily dose received by the children in this study is lower than that obtained by other studies ${ }^{42,72}$. The observed differences in terms of dose received by the subjects in the present study with respect to the others could be due to different study design factors, such as different times of the year, different dosimeter positions and mainly that the skiers in these two papers were professionals who were outdoors for about $8 \mathrm{~h}$. The children in this study received $35 \%$ of ambient erythemal UVR, with values between $12 \%$ and $96 \%$. In the Italian $\mathrm{Alps}^{73}$ obtained a winter median ER of 54\%, with a range of $42-70 \%$. The differences between the two studies could be due to the different positions of the dosimeters, altitudes and orientations of the ski slopes, among others.

As children can suffer vitamin D deficiency in winter due to low levels of UVR, the minimum exposure time necessary to get the skin to produce the minimum recommended daily amount of vitamin D for type III skinned children was found to be 170 minutes a day in the least favourable conditions. As the mean daily exposure time was 276 minutes during the ski sessions, the type II-III skinned children's vitamin D 
needs could be said to be covered all days during the study period. However, type IV skinned children would not cover their daily needs of Vitamina D in the days of UVI 1. However, the results of our study also show that skiers are exposed to erythemal UVR at levels that can damage the skin, cause erythema, and potentially increase the later risk of skin cancer. This result emphasises the need for protective measures against solar radiation, such as high protection sunscreen (30 or higher), sunglasses, a hat and high quality protective clothing when performing this type of outdoor physical activities. The results of this study are also consistent with the guidelines given by the ICNIRP working group ${ }^{79}$, which recommends sun protection for those who plan to be outdoors for prolonged periods at UVI Levels 1 and 2.

This information has been sent to the directors of the Snow School concerned so that the appropriate actions can be taken.

The results also suggest that sun-protection campaigns should be undertaken aimed at children engaged in outdoor sports, including winter activities. 


\section{Acknowledgements}

The authors wish to thank the instructors and children of "The Snow School" for their collaboration in this study. We would like to thank the R\&D\&I Linguistic Assistance Office, Universitat Politècnica de València (Spain) for granting financial support for proofreading this paper.

We acknowledge the NASA mission scientists and Principal Investigators who provided data used in this research effort. Analyses used in this paper were produced with the Giovanni online data system, developed and maintained by the NASA GES DISC.

This research was supported by the Spanish Ministry of Education and Science within the research project CGL2010-15931 and the Generalitat Valenciana within project PROMETEO/2010/064. 


\section{References}

1. L.R. Sklar, F. Almutawa, H.W. Lim and I. Hamzavi, Effects of ultraviolet radiation, visible light, and infrared radiation on erythema and pigmentation: a review, Photochem. Photobiol. Sci., 2013, 12, 54-64.

2. M. Norval, R.M.Lucas, P. Cullen, F.R. de Gruijl, J. Longstreth, Y. Takizawa and J.C. van der Leung, The human health effects of ozone depletion and interactions with climate change, Photochem. Photobiol. Sci., 2011, 10, 199-225.

3. R. Lucas, A.J. McMichael, B. Armstrong and W. Smith, Estimating the global disease burden due to ultraviolet radiation exposure, International Journal of Epidemiology, 2008, 37, 654-67.

4. A. Juzeniene, P. Brekke A. Dahlback A, S. Andersson-Engels, J. Reichrath, K. Moan, M.F. Holick, W.B. Grant and J. Moan, Solar radiation and human health, Rep. Prog. Phys., 2011, 74, 066701 (56pp).

5. A. Cabanes, B. Pérez-Gómez, N. Aragonés, M. Pollán and G. López-Abente, La situación del cáncer en España, 1975-2006, Instituto de Salud Carlos III, Ministerio de Ciencia e Innovación, Madrid 2009.

6. F. Erdmann, J. Lortet-Tieulent, J. Schuz, H. Zeeb, R. Greinert, E.W. Breitbart and F. Bray, International trends in the incidence of malignant melanoma 1953-2008are recent generations at higher or lower risk, International Journal of Cancer, 2013, 132, 385-400. 
7. C. Garbe and U. Leiter, Melanoma epidemiology and trends, Clinics in Dermatology, 2009, 27, 3-9.

8. V. Madan, J. Lear and R.M. Szeimies, Non-melanoma skin cancer, Seminar ww.thelancet.com., February 20 2010, 375, 673-85.

9. World Health Organization, World Cancer Report 2008, International Agency for Research on Cancer, Edited by Peter Boyle and Bernard Levin, Lyon 2008.

10. Cáncer en cifras, Centro Nacional de Epidemiología Instituto de Salud Carlos III, Available at http://193.146.50.130/morta/grafs.php\#grafs, [accessed 15-06-12].

11. GLOBOCAN 2008. World Health Organization, International Agency for Research on Cancer. Available at http://globocan.iarc.fr/, [accessed 18-06-13].

12. M. Saraiya, K. Glanz, P.A. Briss, P. Nichols, C. White, D. Das, S.J. Smith, B. Tannor, A.B. Hutchinson, K.M. Wilson, N. Gandhi, N.C. Lee, B. Rimer, R.C. Coates, J.F. Kerner, J.C. Hiatt, P. Buffler and P. Rochester, Interventions to prevent skin cancer by reducing exposure to ultraviolet radiation: a systematic review, Am. J. Prev. Med., 2004, 27, 422-466.

13. Y. Chang, J.H. Barreto, D.T. Bishop, B.K. Armstrong, V. Bataille, W. Bergman, M. Berwick, P.M. Bracci, J.M. Elwood, M.S. Ernstoff, R.P. Gallagher, A.C. Green, N.A. Gruis, E.A. Holly, Ingvar C, Kanetsky PA, Karagas MR, Lee TK, Le 
Marchand L, Mackie RM, Olsson H, Østerlind A, Rebbeck TR, Sasieni P, Siskind V, Swerdlow AJ, Titus-Ernstoff L, Zens MS and Newton-Bishop JA, Sun exposure and melanoma risk at different latitudes: a pooled analysis of 5700 cases and 7216 controls, International Journal of Epidemiology, 2009, 38, 814-830.

14. L.K. Dennis, M.J. VanBeek, L.E. Beane Freeman, B.J. Smith, D.W. Dawson and J.A. Coughlin, Sunburns and risk of cutaneous melanoma, does age matter: a comprehensive meta-analysis, Ann. Epidemiol., 2008, 18(8), 614-627.

15. B.K. Armstrong and,A. Kricker, The epidemiology of UV induced skin cancer. $J$. Photochem. Photobiol. B, 2006, 63, 8 -18.

16. S. Gandini, F. Sera, M.S. Cattaruzza, P. Pasquini, O. Picconi, P. Boyle and C.F. Melchi, Meta-analysis of risk factors for cutaneous melanoma: II. Sun exposure, Eur. J. Cancer, 2005, 41(1), 45-60.

17. S.A. Oliveria, M. Saraiya, A.C. Geller, M.K. Heneghan and C. Jorgensen, Sun exposure and risk of melanoma, Arch. Dis. Child, 2006, 91,131-8.

18. A.T. Dodd, J. Morelli, S.T. Mokrohisky, N. Asdigian, T.E. Byers and L.A. Crane, Melanocytic Nevi and Sun Exposure in a Cohort of Colorado Children: Anatomic Distribution and Site-Specific Sunburn, Cancer Epidemiol. Biomarkers Prev.,2007, 16(10), 2136-43. 
19. S.K. Balk and the Council on Environmental Health and Section on Dermatology. Ultraviolet Radiation: A Hazard to Children and Adolescents, Pediatrics, 2011, 127, 791-817.

20. J.R. Wong, J.K. Harris, C. Rodriguez-Galindo and K.J. Johnson , Incidence of Childhood and Adolescent Melanoma in the United States: 1973- 2009, Pediatrics, 2013, 131(5), 846-54.

21. M. Jen, M. Murphy and J.M. Grant-Kels, Childhood melanoma, Clinics in Dermatology, 2009, 27, 529-36.

22. J. Bauer, T.L. Diepgen and J. Schmitt, Risk factors of incident melanocytic nevi: a longitudinal study in a cohort of 1,232 young German children, Int. J. Cancer, 2005, 115, 121-6.

23. C.M. Ambros-Rudolph, R. Hofmann, E. Richtig, M. Muller, H.P. Soyer and H. Kerl, Malignant Melanoma in Marathon Runners, Arch. Dermatol., 2006, 142, 1471-4.

24. E. Richtig, C.M. Ambros-Rudolph, M. Trapp, J.K. Lackner, R. HofmannWellenhof, H. Kerl and G. Schwaberger, Melanoma Markers in Marathon Runners: Increase with Sun Exposure and Physical Strain, Dermatology, 2008, 217, 38-44.

25. H. Williams, J. Brett and A. Du Vivier, Cyclist's melanoma, J. of the Royal College of Phys. Of London, 1989, 23(2), 114-5. 
26. V. Lichte, B. Dennenmoser, K. Dietz, H.M. Hafner, B. Schlagenhauff, C. Garbe, J. Fischer and M. Moehrle, Professional risk for skin cancer development in male mountain guides - a cross-sectional study, JEADV, 2010, 24, 797-804.

27. N.J. Downs, P.W. Schouten, A.V. Parisi and J. Turner, Measurements of the upper body ultraviolet exposure to golfers: non-melanoma skin cancer risk, and the potential benefits of exposure to sunlight, Photodermatology, Photoimmunology \& Photomedicine, 2009, 25, 317-24.

28. N.J. Downs, A.V. Parisi and P. Schouten, Basal and squamous cell carcinoma risks for golfers: An assessment of the influence of tee time for latitudes in the Northern and Southern hemispheres, Journal of Photochemistry and Photobiology B: Biology, 2011, 105, 98-105.

29. E.M. Mahé, A. Beauchet, M. de Paula Correa, S. Godin-Beekmann, M. Haeffelin, S. Bruant, et al., Outdoor sports and risk of ultraviolet radiation-related skin lesions in children: evaluation of risks and prevention, British Journal of Dermatologists, 2011, 165, 360-7.

30. F.R. De Gruijl, Sufficient Vitamin D from Casual Sun Exposure?, Photochemistry and Photobiology, 2011, 87, 598-601. 
31. A.R. Webb, R. Kift, J.L. Berry and L.E. Rhodes, The Vitamin D Debate:

Translating Controlled Experiments into Reality for Human Sun Exposure Times, Photochemistry and Photobiology, 2011, 87, 741-5.

32. M. Norval, A.P. Cullen, F. De Gruijl, J. Longstreth, Y. Takizawa, R.M. Lucas, et al., The effects on human health from stratospheric ozone depletion and its interactions with climate change, Photochem. Photobiol. Sci., 2007, 6, 232-51.

33. M.T. Kampman and L.H. Steffense, The role of vitamin D in multiple sclerosis, Journal of Photochemistry and Photobiology B: Biology, 2010, 101, 137-41.

34. A. Zittermann and J.F. Gummert, Sun, vitamin D, and cardiovascular disease, Journal of Photochemistry and Photobiology B: Biology, 2010, 101, 124-9.

35. W.B. Grant, Relation between prediagnostic serum 25-hydroxyvitamin D level and incidence of breast, colorectal, and other cancers, Journal of Photochemistry and Photobiology B: Biology, 2010, 101, 130-6.

36. E.M. John, J. Koo and G.G. Schwartz, Sun exposure and prostate cancer risk: evidence for a protective effect of early-life exposure, Cancer Epidemiol. Biomarkers Prev., 2007, 16, 1283-6.

37. EUROMELANOMA Campaign. Available at http://www.euromelanoma.org/spain/home-1, [accessed 09-04-13]. 
38. A.J. Stratigos, A.M. Forsea, R.J.T. van der Leest, E. de Vries, E. Nagore, J.L. BulliardL, M. Trakatelli, J. Paoli, K. Peris, J. Hercogova, M. Bylaite, T. Maselis, O. Correia and V. del Marmol, Euromelanoma: a dermatology-led European campaign against nonmelanoma skin cancer and cutaneous melanoma. Past, present and future, British Journal of Dermatology, 2012 167, 99-104.

39. T.B. Fitzpatrick, The validity and practicality of sun-reactive skin types I through VI, Arch. Dermatol., 1988, 124, 869-71.

40. Biosense Laboratories, Available at www.biosense.de/home-e.htm, [accessed 16-0113].

41. M.A. Serrano, J. Cañada and J.C. Moreno, Erythemal Ultraviolet exposure of cyclists in Valencia, Spain, Photochemistry and Photobiology, 2010, 86, 716-21.

42. M. Moehrle and C. Garbe, Personal UV dosymetry by Bacillus subtilis Spore Films, Dermatology, 2000, 200, 1-5.

43. D.L. O'Riordan, K. Glanz, P. Gies and T. Elliott, A Pilot Study of the Validity of Self-reported Ultraviolet Radiation Exposure and Sun Protection Practices Among Lifeguards, Parents and Children, Photochem. Photobiol., 2008, 84(3), 774-778.

44. A. Milon, P.E. Sottas, J.L. Bulliard and D. Vernez, Effective exposure to solar UV in building workers: influence of local and individual factors, Journal of Exposure Science and Environmental Epidemiology, 2007, 17, 58-68. 
45. M.A. Serrano, J. Cañada and J.C. Moreno, Erythemal Ultraviolet exposure in two groups of outdoor workers in Valencia, Spain, Photochemistry and Photobiology, 2009, 85, 1468-73.

46. M.A. Serrano, J. Cañada and J.C. Moreno, Ultraviolet exposure for different outdoor sports in Valencia, Spain, Photodermatology, Photoimmunology \& Photomedicine, 2011, 27, 311-7.

47. Y. Furusawa, L.E. Quintern, H. Holtschmidt, P. Koepke and M. Saito, Determination of erythema-effective solar radiation in Japan and Germany with a spore monolayer film optimized for the detection of UVA and UVA - results of a field campaign, Appl. Microbiol. Biotechnol., 1998, 50, 597-603.

48. N. Munakata, S. Kazadzis, A.F. Bais, K. Hieda, G. Ronto, P. Rettberg and G. Horneck, Comparisons of Spore Dosimetry and Spectral Photometry of Solar-UV Radiation at Four Sites in Japan and Europe, Photochemistry and Photobiology, 2000, 72(6), 739-45.

49. C.I.E.Commission Internationale de l'Eclairage (1998) Erythema Reference Action Spectrum and Standard Erythema Dose. CIE S007E-1998. CIE Central Bureau, Vienna, Austria.

50. CIE, The International Commission on Illumination. Standard Erythema Dose, a Review. CIE 1997: 125, Vienna. 
51. L.E. Quintern, Y. Furusawa, K. Fukutsu and H. Holtschimdt, Characterization and application of UV detector spore-films: the sensitivity curve of a new detector system provides good similarity to the action spectrum for UV-induced erythema in human skin, J. Photochem. Photobiol. B:Biology, 1997, 37, 158-66.

52. G. Seckmeyer, B. Mayer and G. Bernhard, The 1997 Status of Solar UV Spectroradiometry in Germany: Results from the National Intercomparison of UV Spectroradiometers, with contributions from Albold A., Baum W., Dehne K.,

Feister U.,Gericke K., Grewe R., Gross C., Sandmann H., Schreiber J., Seidlitz H.K., Steinmetz M., Thiel S., Wallasch M. and Weller M.. GarmischPartenkirchen, Germany, Fraunhofer Institute for Atmospheric Environmental research 1998, 55/98, ISBN: 3-8265-3695-9.

53. OMI/Aura Online Visualization and Analysis. Daily Level 3 Global Gridded Products. Available at http://gdata1.sci.gsfc.nasa.gov/daacbin/G3/gui.cgi?instance_id=omi, [accessed 28-06-13].

54. O. Engelsen and A. Kylling, Fast simulation tool for ultraviolet radiation at the Earth's surface, Optical Engineering, 2005, 44 (4), 041012 doi:

10.1117/1.1885472, Available at http:/ / nadir.nilu.no / olaeng / fastrt / fastrt.html, [accessed 02-04-12].

55. NASA. Ozone Monitoring Instrument. Available at http://ozoneaq.gsfc.nasa.gov/ozone_overhead_all_v8.md, [accessed 2-04-12]. 
56. J. G. Acker and G. Leptoukh, Online Analysis Enhances Use of NASA Earth Science Data, Eos, Trans. AGU 2007, 88( 2), 14-17.

57. A.R. Webb and O. Engelsen, Calculated Ultraviolet Exposure Levels for a Healthy Vitamin D Status, Photochemistry and Photobiology 2006, 82(6), 1697-1703. Available at http://nadir.nilu.no/ olaeng/fastrt/VitD_quartMEDandMED_v2.html [accessed 02-04-12].

58. ICNIRP (International Commission on Non-Ionizing Radiation Protection) Global Solar UV Index. ICNIRP-1/95, Oberschleissheim, Germany.

59. World Health Organization. Global Solar UV Index: A Practical guide. WHO 2002, Geneva, Switzerland.

60. OMI UVB Algorithm Documents. Available at http://disc.sci.gsfc.nasa.gov/Aura/data-holdings/OMI/omuvbd_v003.shtml, [accessed 26-06-13].

61. A. Tanskanen, A.Lindfors, A. Maatta, N. Krotkov, J. Herman, J. Kaurola, T. Koskela, K. Lakkala, V. Fioletov, G. Bernhard, R. McKenzie, Y. Kondo, M. O’Neill, H. Slaper, P. denOuter, A. Bais, and J. Tamminen, Validation of daily erythemal doses from ozone monitoring Instrument with groundbased UV measurement data, J. Geophys. Res., 2007, 112, D24S44, doi:10.1029/2007JD008830. 
62. V. Buchard, C. Brogniez, F. Auriol, B. Bonnel, J. Lenoble, A. Tanskanen, B. Bojkov, and P. Veefkind, Comparison of OMI ozone and UV irradiance data with ground-based measurementsat two French sites, Atmos. Chem. Phys., 2008, 8, $4517-4528$.

63. N. A. Krotkov, J. Herman, P.K. Bhartia, C. Seftor, A. Arola, J. Kaurola, S. Kalliskota , P. Taalas, and I. Geogdzhaev, Version 2 TOMS UV algorithm: problems and enhancements, Opt. Eng., 2002, 41, 3028-3039.

64. G. Seckmeyer, D, Pissulla, M. Glandorf, D. Henriques, B. Johnsen, A. Webb, A. Siani, A. Bais, B. Kjeldstad, C. Brogniez, J. Lenoble, B. Gardiner, P. Kirsch, T. Koskela, J. Kaurola, B. Uhlmann, H. Slaper, P. den Outer, M. Janouch, P. Werle, J. Grobner, B. Mayer, A. de la Casiniere, S. Simic and F. Carvalho, Variability of UV Irradiance in Europe, Photochemistry and Photobiology, 2008, 84, 172-179.

65. K. Vanicek, T. Frei, Z. Litynska and A. Schnalwieser, UV-index for the public, COST-713 Action (UV-B Forecasting) 2000, Brussels, 27 p.

66. A. Pribullova and M. Chmelik, Effect of altitude and surface albedo variability on global UV:B and total radiation under clear-sky condition, Contributions to Geophysics and Geodes., 2005, 35(3), 281-298.

67. M.B. Blumthaler, W. Ambach and R. Ellinger, Increase in solar UV radiation with altitude, Journal of Photochemistry and Photobiology B: Biology, 1997, 39 130-4. 
68. Y. Sola, J. Lorente, E. Campmany, X. de Cabo, J. Bech, A. Redan, et al., Altitude effect in UV radiation during the Evaluation of the Effects of Elevation and Aerosols on the Ultraviolet Radiation 2002 (VELETA-2002) field campaign, $J$. Geophys. Res., 2008, 113, D23202, doi:10.1029/2007JD009742.

69. D.A. Schmucki and R. Philipona, UV radiation in the Alps: The altitude effect, Opt. Eng., 2002, 41(12), 3090-5.

70. P. Aceituno-Madera, A. Buendía-Eisman, F.J. Olmo, J.J. Jiménez-Monleón and S. Serrano-Ortega, Melanoma, Altitude, and UV-B Radiation, Actas Dermosifiliogr., 2011, 102, 199-205.

71. S. Rosso, R. Zanetti, M. Pippione and H. Sancho-Garnier, Parallel risk assessment of melanoma and basal cell carcinoma: skin characteristics and sun exposure, Melanoma Res., 1998, 8(6), 573-83.

72. E.G. Rigel, M.G. Lebwohl, A.C. Rigel ans D.S. Rigel, Ultraviolet radiation in Alpine skiing, Arch. Dermato., 2003, 139, 60-2.

73. A.M. Siani, G.R. Casale, H. Diémoz, G. Agnesod, M.G. Kimlin, C.A. Lang and A. Colosimo, Personal UV exposure in high albedo alpine sites, Atmos. Chem. Phys., 2008, 8, 3749-60.

74. M. Allen and R. McKenzie, Enhanced UV exposure on a ski-field compared with exposures at sea level, Photochem. Photobiol. Sci., 2005, 4, 429-37. 
75. M. Allen and R. McKenzie, UV exposure on New Zealand ski-fields. UV Radiation and its Effects: an update, Royal Society of New Zealand 2006: Miscellaneous Series 68, Wellington: 70-71.

76. P. Weihs, Influence of ground reflectivity and topography on erythemal UVradiation on inclined surfaces, Int. J. Biometeorol., 2002, 46, 95-104.

77. A. Oppenrieder, P. Hoeppe and P. Koepke, Routine measurement of erythemally effective UV irradiance on inclined surfaces, Journal of Photochemistry and Photobiology B: Biology, 2004, 74, 85-94.

78. A.V. Parisi and M.G. Kimlin, Horizontal and sun-normal spectral biologically effective ultraviolet irradiances, J. Photochem. Photobiol. B: Biol., 1999, 53, 7074.

79. S. Allinson, M. Asmuss, C. Baldermann, J. Bentzen, D. Buller, N. Gerber, et al., ICNIRP: VALIDITY AND USE OF THE UV INDEX: REPORT FROM THE UVI WORKING GROUP, SCHLOSS HOHENKAMMER, GERMANY, 5-7 DECEMBER 2011, Health Physics, 2012, 103(3), 301-6. 